\title{
Automatization of the Ecodesign Process of Small Household Appliances based on CAD 3D System
}

\author{
Radosław WICHNIAREK, Damian GRAJEWSKI, Jacek DIAKUN, Ewa DOSTATNI, Anna KARWASZ
}

\begin{abstract}
A new approach to product quality assessment taken by manufacturers integrates environmental aspects. Design for the environment, also referred to as ecodesign or sustainable design, is an innovative approach to the traditional design process. It focuses on compliance with ecological standards at an early stage of design in CAD 3D environment. In this paper, main objectives of the ecodesign process automation method based on a CAD 3D system are presented. The ecodesign process of a small household appliance is analyzed. The main features of a dedicated software application with a graphical interface, which runs independently of the CAD 3D system, are presented.
\end{abstract}

Keywords: automatization; CAD 3D; design for recycling; ecodesign

\section{INTRODUCTION}

At an early stage of product design, a number of different aspects related to technical and economic requirements of the new product must be considered. Therefore, the design process is a complex task which involves processing of vast amounts of data. Quite often, the designer must choose among various methods of solving engineering problems while maintaining creativity. The design stage determines the entire product life cycle, as decisions made in this phase affect the cost of production and maintenance. Support can be obtained through the use of IT tools. CAD 3D systems support geometric modelling and creation of digital technical 2D and $3 \mathrm{D}$ documentation to obtain a digital representation of the designed product.

Nowadays many enterprises are using CAD 3D software as an effective and supportive tool in the product design process. The profile of the future product in a CAD 3D system typically includes features such as geometry, kinematics, material properties, technological components, effective manufacturing and assembly.

As a standard, the design process focuses not only on functionality, but also on the manufacturing process (e.g. material flow [1, 2], assembly [3]).

Nowadays, a new approach to project quality assessment is being adopted. It involves identification of environmental aspects and is often referred to as design for the environment, design in accordance with the principles of sustainable development, or ecodesign. It introduces a new dimension to the traditional product design process.

Ecodesign is implemented for a number of reasons. The main determinants, divided into internal and external factors, are described in the authors' previous papers [4, 5].

With regard to the design features of the product, ecodesign is meant to fulfil the requirements of $\mathrm{EU}$ directives $[6,7,8]$ and environmental standards, related primarily to:

- use of mutually compatible biodegradable materials with the smallest possible environmental footprint,

- use of connections between components which ensure product recyclability.
However, implementation of ecodesign cannot compromise product functionality or price competitiveness. Having this in mind, the design work becomes even more complex. In response to these needs, a lot of new IT solutions have been presented to the market in order to aid ecodesign process, e.g. at the stage of selection of materials and connecting components.

One of them is the software presented in this article.

\section{METHOD OF RECYCLING-ORIENTED PRODUCT ASSESSMENT DURING DESIGN PROCESS}

\subsection{Computer-Aided Ecodesign}

Over the last few years more and more developers introduced specialised kinds of software that support ecodesign decision-making process. The functionality of selected methods and tools has been analysed [9-18]. Special consideration was taken to the recycling methods, balancing the ecological aspects of materials and product disassembly. Additional systems, integrated with certain software modules and databases, gather the required information. Depending on the selected software, the information and knowledge are constantly updated, assuring compliance with current environmental requirements. In conclusion, most of the mentioned software supports routine control of the designed product in terms of the ecodesign requirements and recommendations [19]. Some of them are part of more complex methodologies (e.g. Design for Excellence DFX) [20].

Alternative group of IT tools that are used for ecodesign are additional modules for CAD 3D systems. For example, Sustainable Materials Assistant ${ }^{\circledR}$ developed by Autodesk Labs. It is a complex tool that assists the designer in order to select the correct and environmentally friendly materials, in order to decrease the environmental impact of designed products while ensuring technical (e.g. materials) coefficients $[4,19,21]$. The next example is SolidWorks Sustainability module that can be used for practical implementation of selected sustainable development strategies at the design phase. Above mentioned module is related to the $\mathrm{GaBi}$ software in scope of process models and life cycle assessment databases. It takes into account key environmental 
indicators such as carbon footprint, total energy consumption, and impact on air and water quality [22].

In [23] authors developed a prototype of decision support module for polymer material selection considering some environmental issues, which may be used within the product design engineering process.

The above described examples show that the need to provide the tools to evaluate and consider the environmental impact of the designed product was noticed by CAD 3D system developers. However, most of the current market solutions were developed as additional modules, integrated into specific CAD 3D software.

In comparison to the commercial IT tools, authors developed the method that supports the design of recycling-oriented products. It belongs to the group of software discussed above, but it allows designers to carry out the recyclability assessment of the selected product in different CAD 3D systems [5, 19]. The main assumptions of authors' methodology are described in the next chapter.

\subsection{Assumptions of the Method}

The existing IT solutions are mainly used to perform a general environmental analysis based on LCA approach and use various types material databases [19].

The authors' method supports product recyclability evaluation. All developed algorithms are available for the user of the CAD 3D system already at the design stage. They are based on the recycling product model (RpM). The distinguishing feature of proposed method is the use of the agent technology described in details in previous publications [5, 24, 25].

The created application has a modular structure. One module operates inside the CAD3D system (RpM model) and the other operates as external application (agent system which conducts the recycling analysis, calculates the evaluation measurements, collects and stores data from previously completed projects) [24].

There is common procedure for recycling-oriented assessment of each product [26]:

- creation of extended product structure in CAD 3D system,

- creation of material attributes and geometric constraints for assembly,

- formation of the RpM,

- execution of the recycling-oriented product analysis.

For the purpose of recycling assessment of the designed product, additional input into the CAD 3D system is required. In details, it is a data on product recyclability properties combined with a standard geometric 3D model. All this data constitute the recycling product model (RpM) [24, 26].

The RpM consists of the following elements [26]:

- extended product structure,

- extended material attributes,

- disassembly attributes (data on the disassembly process),

- product categorization.

A detailed description of the RpM structure and rules needed for proper and effective functioning of the model in the CAD 3D environment were presented in authors' previous papers $[24,26]$.

In short, the RpM contains data necessary for a comprehensive product recyclability evaluation as early as at the design stage. Such an approach allows the designer to select solutions that facilitate future disassembly, and choose the most suitable materials in view of product recyclability.

The RpM is used as a basis for the development of an additional application that facilitates the design process taking into account the recycling aspects. The IT tool includes a knowledge base that stores data from previous projects. Based on the content of the knowledge base, the application automatically generates suggestions of useful solutions which take into account the aspects of recycling. It is made possible thanks to the use of agent technology. The designer's activity in the CAD 3D system is tracked by the agents that monitor the changes made in the design. Agent system assesses the impact of design changes in real time and provides suggestions how to improve the product to be more recyclable [27].

In conclusion, the authors' IT tool provides automatic support for the computer-aided ecodesign process. It eliminates:

- the need to reconsider the product structure,

- the need to manually aggregate the parameters relevant for the recyclability evaluation,

- the need to re-introduce above mentioned parameters to third party systems [4].

A brief description of how the methodology is applied is presented in the next chapter.

\section{Implementation of RpM in CAD 3D System}

In industrial applications, the most popular CAD systems for creating $2 \mathrm{D}$ and 3D digital documentation allow the user to increase productivity by automating some design activities [28]. This can be done in two ways. One way, at the level of a CAD 3D system, utilizes a programming language for the definition of sets of procedures and functions of CAD $3 \mathrm{D}$ to be carried out automatically or with partial engagement of the user. They are available as normal icons in the user interface, or can be run using command lines. The other way of design automation in a CAD 3D system is the use of external programs / scripts that have their own GUI, and are run independently from CAD 3D systems. The scripts use libraries provided by manufacturers of CAD $3 \mathrm{D}$, so they can communicate with the system and control the operation of selected system functions [29].

Automated programming in CAD 3D systems not only minimizes repetitive tasks, but also introduces new functions, unavailable before in certain CAD 3D systems [30]. CAD 3D systems with closed structure data provide little possibility for introducing new program features, or make the automation process inefficient.

The authors took this into account and for the purpose of the study selected CATIA V5 a system where the RpM can be introduced.

From the point of view of the RpM implementation, CATIA V5 is not perfect. It imposes certain restrictions, which reduce the effectiveness of software solutions. However, the authors selected a universal form of 
implementation, so that the solutions adopted can be used in other CAD 3D systems without any major changes to the principle of operation of the proposed algorithms.

\subsection{Data Structure}

A challenging task was to introduce a set of RpM inputs for the files which contain information about the product design features. In CATIA, "CatPart" files correspond to single elements of the product structure, while "CATProduct" files define product assemblies. It was decided to store data, as additional properties at certain structure levels, in the files corresponding to particular parts or assemblies. The number of additional features which can be defined in a single file is limited to 256. For effective use of data entry, logical entity data is stored as a list of text elements, separated arbitrarily by set separators.

Data which may contain the RpM was divided into three types. It can be entered using a specially designed graphical user interface, or manually, by changing the model structure using the CAD 3D tools and commands. Obviously, only the first solution ensures full consistency of the model and ensures correct operation of the software.

The first type of data (general information about product) is encrypted at the top level structure of the product. Defined in the first place, it includes information about the materials, tools, signature design and product category.

The selected CAD 3D system contains its own material library. However, the library does not support expansion of material properties for recyclability. Therefore, authors decided to introduce a new library of materials and tools for disassembly. This solution increases versatility and possibilities of implementation of the method in other CAD 3D systems. The new library, in the form of an external file, can be loaded and stored in CAD files using a dedicated import interface. A separate application to manage content of the libraries was created. (Fig. 1).

Another type of data in the model describes product structure. The data is stored in product structure files, except for the top-level assembly. Each individual component or subassembly can be considered a separate entity, without reference to the top-level structure of the product. Each item of the product structure can function as a connected item, a connecting item, or it can have a special status. The special status indicates that the item has a complex structure, and to minimize the amount of data stored as product geometry, it is not presented together with the full structure of recycling. For special status items, the level of recycling and the related costs must be specified explicitly in the CAD 3D system. For each component, information about the material is required.

Finally, the last type of data describes the connections (connection joints) used between components. This data is stored in "CATProduct" files. Each of the assemblies in the product structure must have at least one connection joint. Each joint has a set of attributes describing:

- sort of connection (separable, inseparable),

- type of connection (e.g. thread),

- whether disassembly is possible,

- estimated time of disassembly,

- estimated amount of work related to disassembly,

- signature of the connection,

- set of connected and connecting elements,

- tools necessary for dismantling the connection.

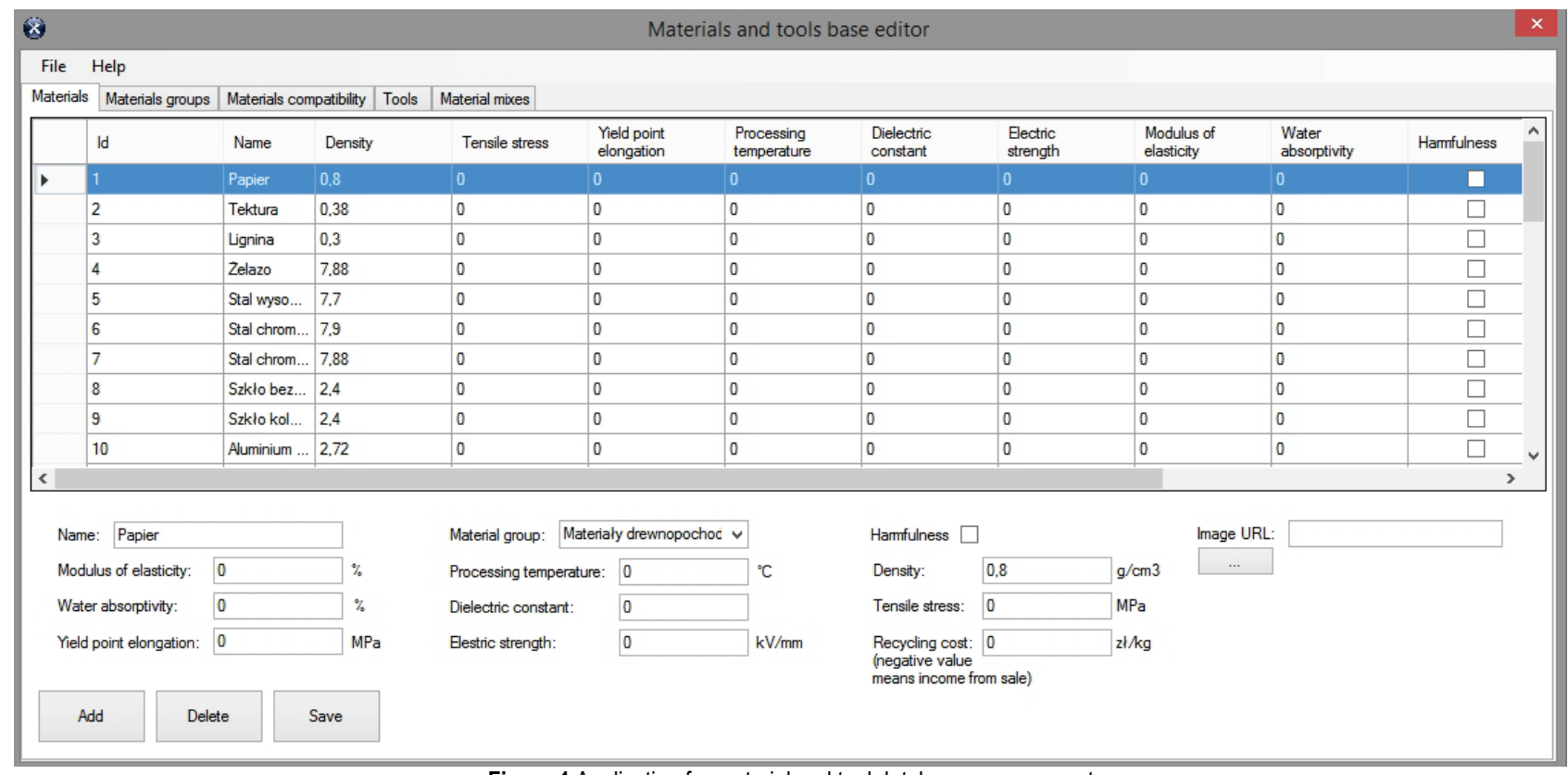

Figure 1 Application for material and tool database management

\subsection{Graphical User Interface}

The graphical user interface (GUI) was created using the Microsoft Forms 2.0 library, while the script code was developed in Visual Basic for Applications. Four command windows are provided:

- global settings,

- properties of assembly elements,

- connection joints, 
- $\quad$ choice of tools for disassembly.

The most time consuming is the definition of connection joint settings (Fig. 2). This window is only available for assemblies with at least two components assigned. The process of defining a new connection follows a strict procedure, so a built-in algorithm prompts the user to use certain values entered at previous steps of the definition. Currently inactive components are greyed out. The script prevents the user from saving incomplete or inconsistent data.
In addition, certain essential functions and procedures are embedded into modules that do not have a graphical representation, and are responsible for:

- materials and tools database import,

- checking the consistency of RpM data,

- $\quad$ export of data to XML.

The command windows are run in the same way as other standard command windows in CATIA. Once entered, data can be edited and reset.

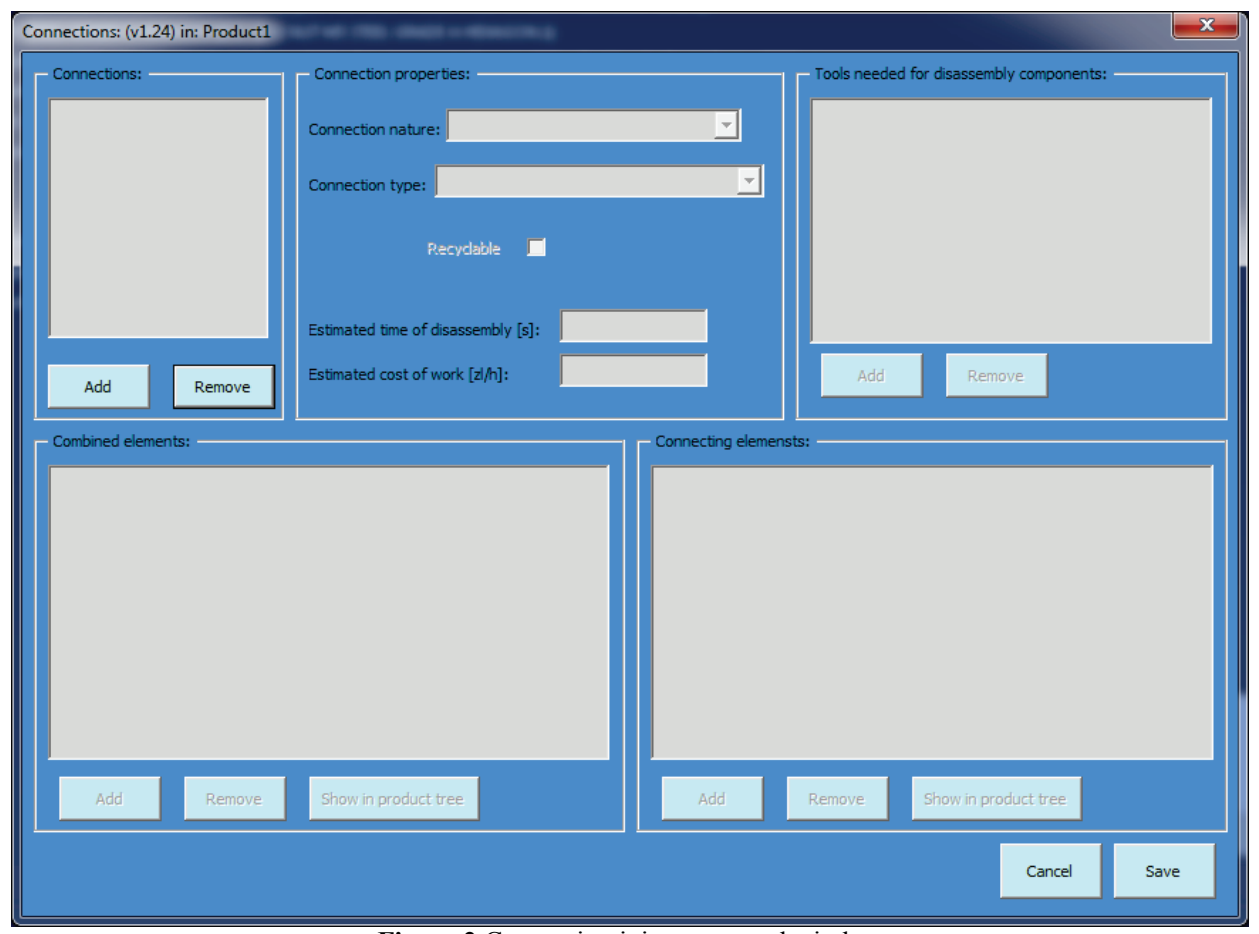

Figure 2 Connection joint command window

\subsection{Export of the RpM Data}

Data gathered from CAD 3D system is delivered to the agent system, where algorithms perform a recycling analysis and the calculated indicators are displayed on the screen. For this purpose, it was necessary to develop a data export module. The XML data exchange format, which is independent of the operating system and easy to interpret even without dedicated software, is used (Fig. 3).

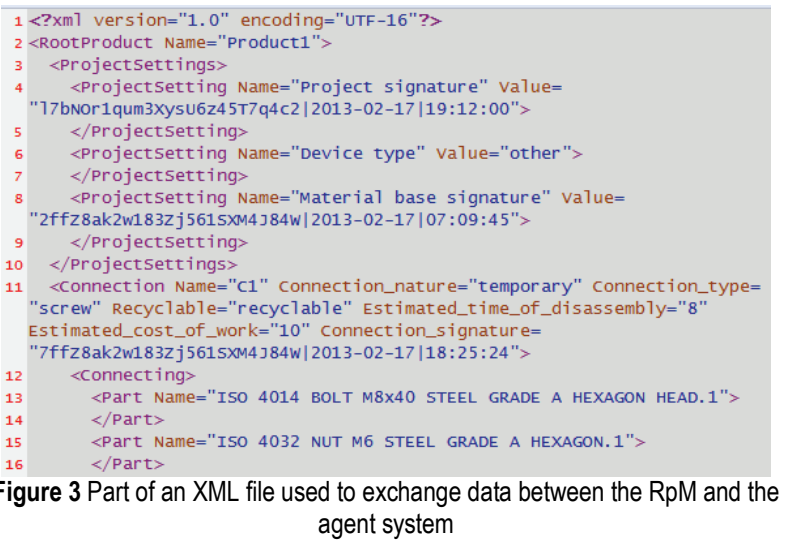

In order to reduce the amount of data exchanged between the CAD 3D system and the agent system, the file with the material database and tools for disassembly is not transmitted. The XML file only contains the signature of the database used for entering the RpM data. Units of measurement and names of assembly items can be adapted to the requirements of the specific CAD 3D system where the RpM will be implemented.

\section{RECYCLABILITY EVALUATION IN THE PRODUCT DESIGN PROCESS}

The procedure of recycling assessment of the designed product (small household appliance) in CAD 3D system will be described. The basic assumption was to supplement the geometric 3D model that included already numerous combinations of joints, with material and disassembly attributes. These attributes were necessary to carry out the analysis and the recyclability evaluation (calculations were performed with the support of the agent system) [4]. The first stage of work consisted in preparing all the necessary 3D models of the product (Fig. 4). Then all necessary geometrical constraints were defined. 


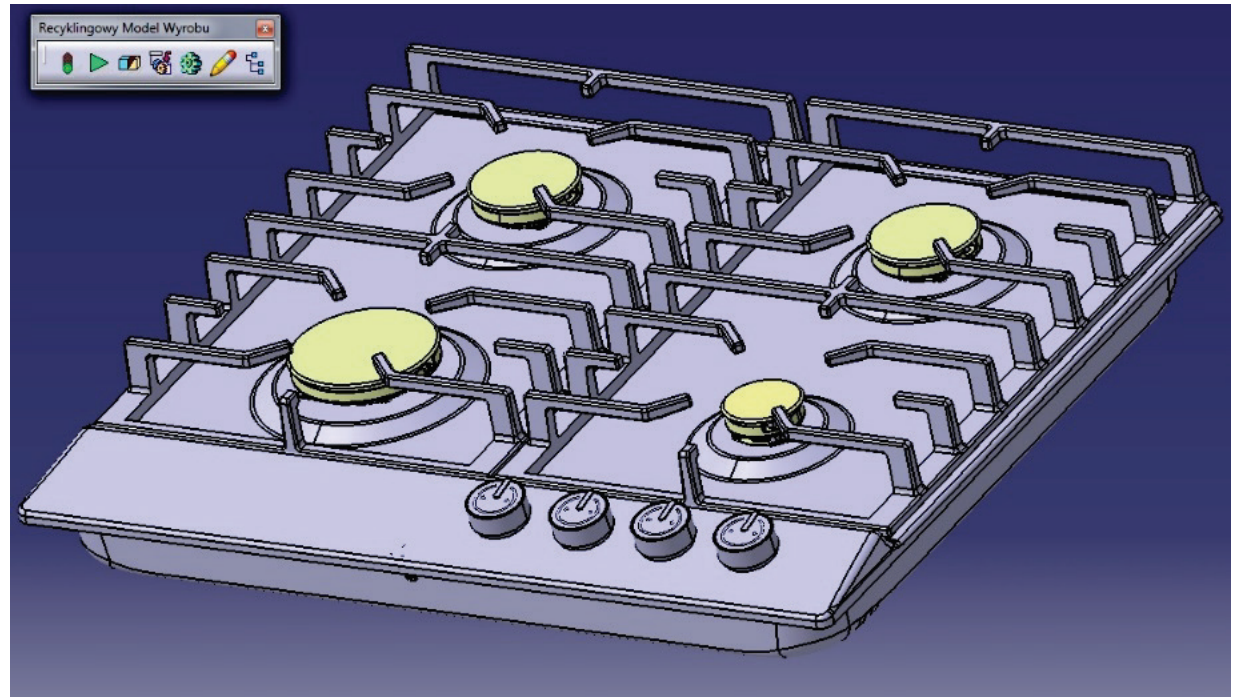

Figure 4 Household appliance - CAD 3D model [4]

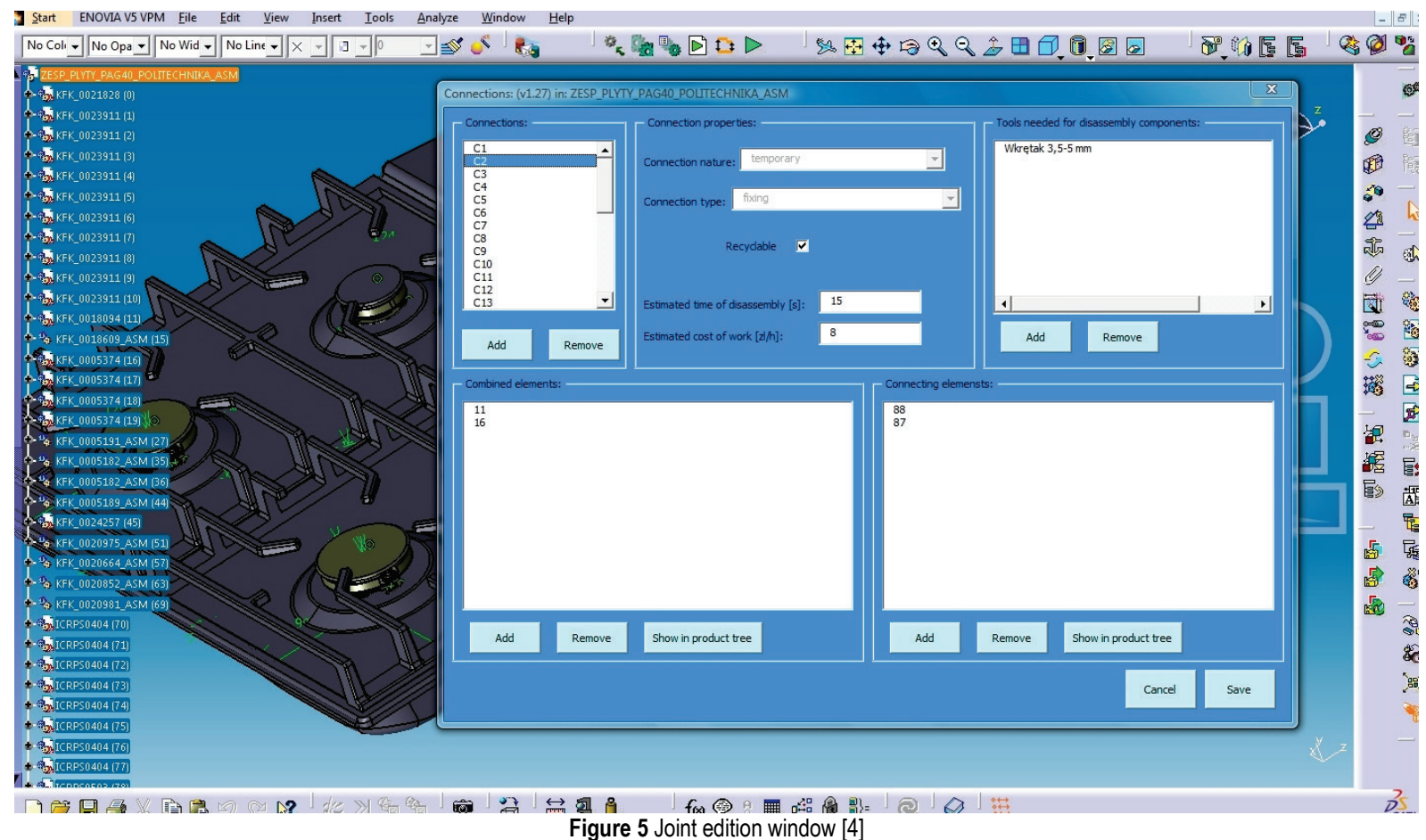

Based on the digital 3D CAD model of the product, it was necessary to develop the RpM model using a graphical user interface in CATIA environment [26]. Specified parts had to be given material attributes - using a specially prepared material database that was developed and uploaded to the system. Basic groups of construction materials and plastics were listed in database in which compatibility matrix was also defined [4].

The next step was to create a model of connections between elements of the product. Each element must be assigned to a specific group (considering its function in the joint: connecting, combined, or connecting-combined) [4]. After assigning the properties of all elements of the assembly, it was necessary to define the connection constraints between the elements (Fig. 5). Each connection had to consist of at least two connected elements. The prepared algorithm verified the correctness of the data, and above all it prevented the user from saving information before this basic condition is met.
At any time, the user can view and edit the list of elements covered by a common binding. He can also indicate elements in the project that meet one of the following criteria:

- its immediate parent element in the product structure is the element for which a joint is declared,

- it is one of the combined elements,

- $\quad$ it is not one of the elements combined by the declared joint [4].

It is worth mentioning that the minimum number of connecting elements that are required for a correct connection depends on the type of connector. In addition, the RpM model is supplemented with information on the tools needed to dismantle the connection as an additional feature of the declared connection.

Further recycling analysis of the designed product was supported by the agent system. RpM data is sent from the $3 \mathrm{D}$ CAD system to the agent system using the data 
exchange interface, which in turn is based on a universal data exchange format [4]. The agent system informs about the values of the measures of the product recycling assessment, for example the level of recycling of each element (basic or complex) of the product being designed
(Fig. 6). The influence of each element on the ratio of the entire product is also calculated [4]. If the agent system detects errors during the analysis (e.g. inconsistency in the product structure), an appropriate warning will be displayed.

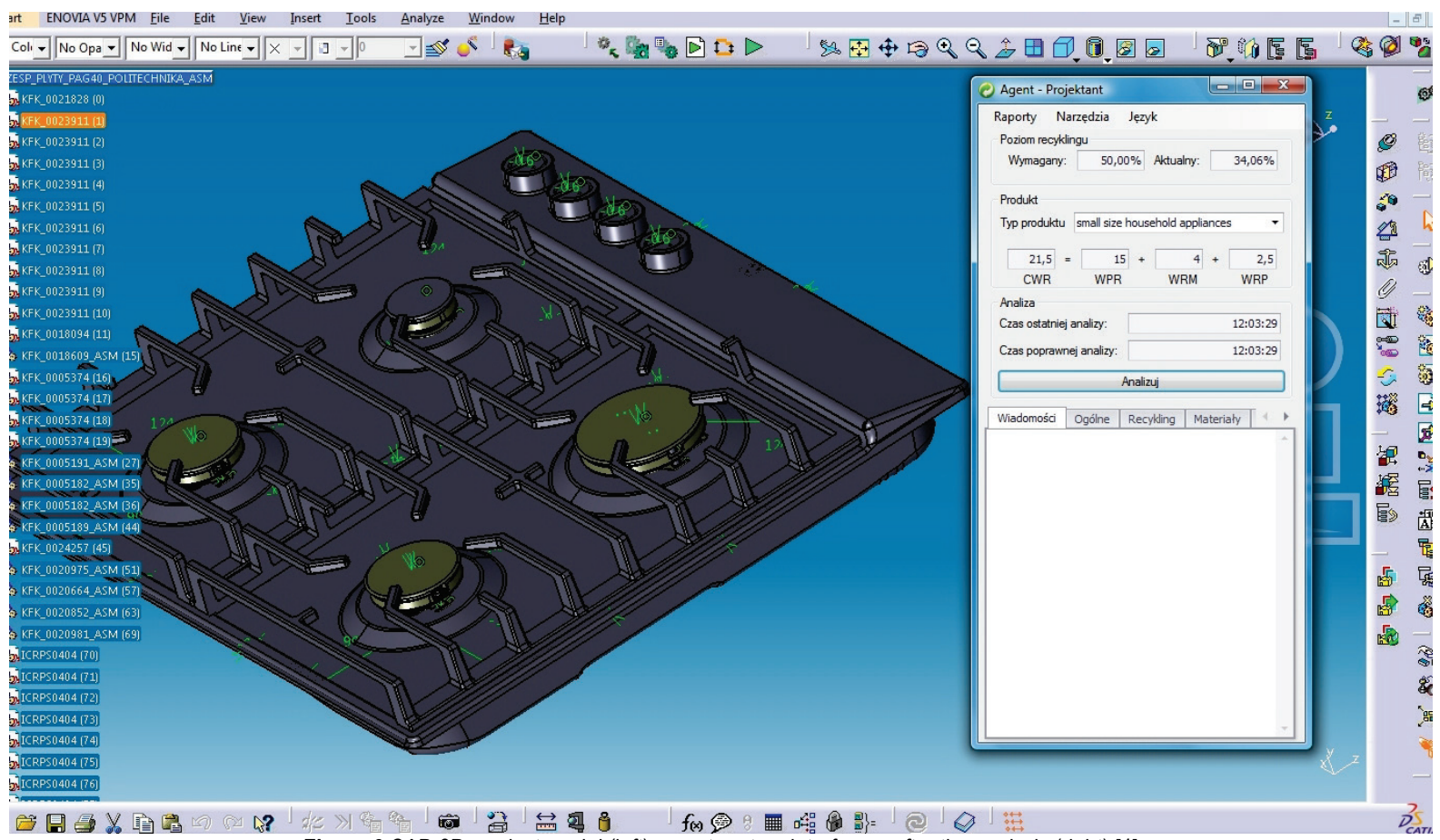

Figure 6 CAD 3D product model (left), agent system interface - after the analysis (right) [4]

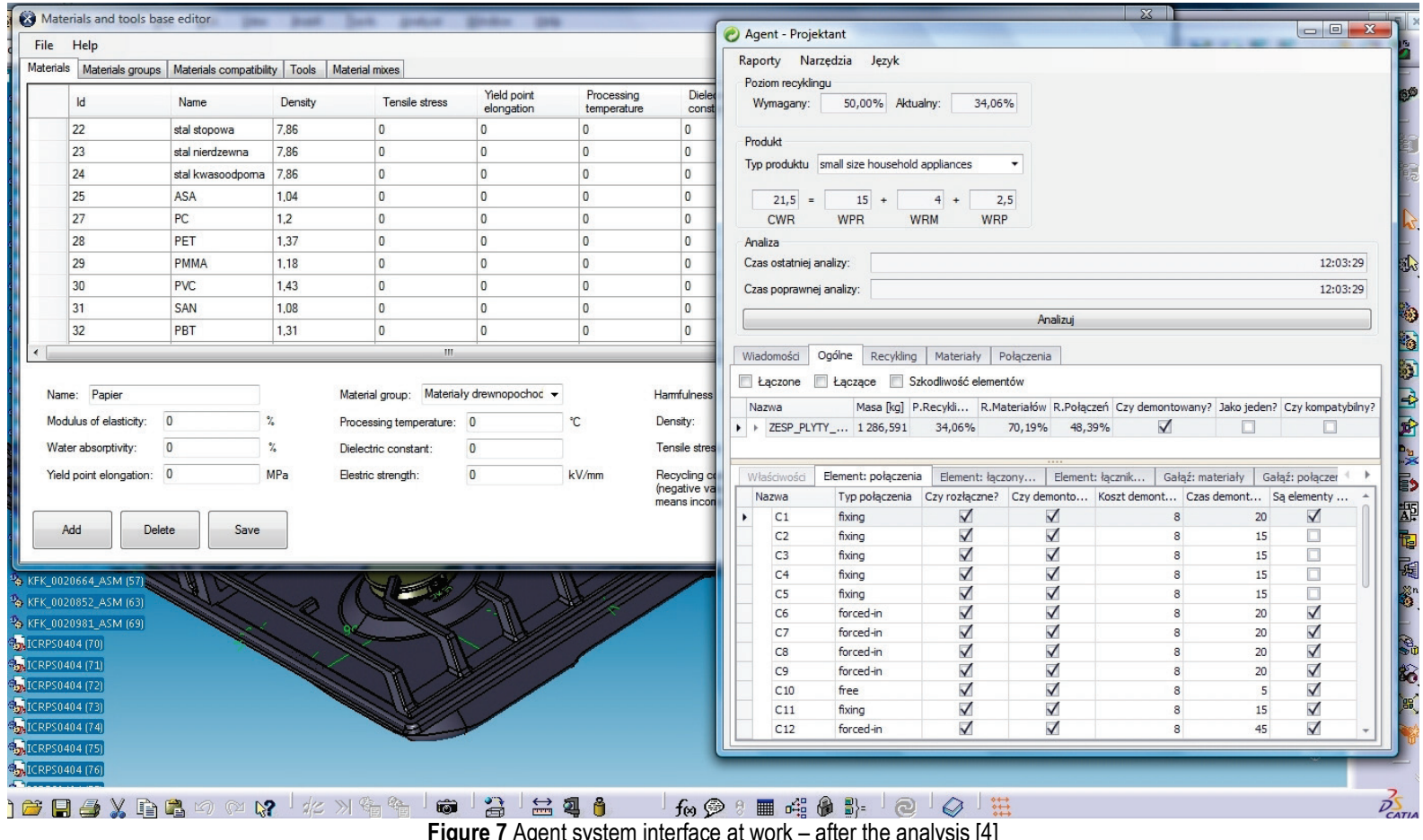

Figure 7 Agent system interface at work - after the analysis [4]

In conclusion, the user receives a solution thanks to which he can efficiently test many variants of the developed product, changing selected parameters that may influence the results of the reusability assessment (eg types of connections or materials). Thanks to this, he can compare and assess the impact of changing the chosen parameter on the results of the recycling assessment (Fig. 7) $[4]$.

\section{CONCLUSION AND FUTURE WORK}

This paper presents a tool implemented in a CAD 3D system that can be successfully used to help designers in the process of ecodesign. Main advantages of the proposed solution:

1) It eliminates the need to parallel the designer's work in two independent programs (CAD 3D system and 
an independent application for ecodesign support) thus reducing the amount of work required and integrating ecodesign into the design process.

2) All design data can be stored in one file together with the 3D model of the product.

3) Authors' algorithm is universal and can be implemented in any CAD 3D system that supports automation of the design process.

Furthermore, it was decided to isolate the process of recycling data collection (the CAD $3 \mathrm{D}$ system) from the process of calculating indicators for the product environmental level assessment (the agent system). As a result, the proposed solution supports simultaneous use by multiple users. The agent system does not require maintenance by the user and is accessible from the network, so all algorithm alterations (for example, an update to meet the requirements of new EU directives) become instantly available to all users. In addition, data collected in previous projects can be utilized in new projects, since prompts for possible changes to the design are displayed.

The RpM is expandable for additional attributes and features thanks to the proposed method of implementation. In summary, it is an IT tool that can be constantly developed and adapted to both the changing legal regulations and internal needs of the company.

Further development of the proposed methodology will rely on recognition of the possibility of integration with KBE systems. It is planned to implement a knowledge base about products and product families, with a particular focus on ecodesign.

A wider context of formalized knowledge available to the designer in the product design process facilitates the decision-making process concerning the materials or combinations used.

\section{REFERENCES}

[1] Krolczyk. J. B., Krolczyk, G. M., Legutko, S., Napiorkowski, J., Hloch, S., Foltys, J. \& Tama, E. (2015). Material flow optimization - a case study in automotive industry. Tehnički vjesnik, 22(6), 1447-1456.

[2] Krolczyk, G., Legutko, S., Krolczyk, J. \& Tama, E. (2014). Materials flow analysis in the production process - case study. Applied Mechanics and Materials, 474, 97-102. https://doi.org/10.4028/www.scientific.net/AMM.474.97

[3] Suszynski, M., Zurek, J. \& Legutko, S. (2014). Modelling of assembly sequences using hypergraph and directed graph. Tehnički vjesnik, 21(6), 1229-1233.

[4] Dostatni, E., Diakun, J., Grajewski, D., Wichniarek, R. \& Karwasz A. (2015). Functionality assessment of ecodesign support system. Management and Production Engineering Review, 6(1), 10-15. https://doi.org/10.1515/mper-2015-0002

[5] Dostatni, E., Diakun, J., Hamrol, A. \& Mazur, W. (2013). Application of Agent Technology for Recycling-Oriented Product Assessment. Industrial Management \& Data Systems, 113(6), 817-839. https://doi.org/10.1108/IMDS-02-2013-0062

[6] Directive 2002/95/EC of the European Parliament and of the Council of 27 January 2003 on the restriction of the use of certain hazardous substances in electrical and electronic equipment. 2003. http://eur-lex.europa.eu/legal-content/ EN/TXT/?uri=CELEX:32002L0095 (27.05.2016)
[7] Directive 2002/96/EC of the European Parliament and of the Council of 27 January 2003 on waste electrical and electronic equipment (WEEE). 2003.

http://eur-lex.europa.eu/legal-content/EN/TXT/?uri= CELEX:32002L0096 (27.05.2016)

[8] ISO/TR 14062, Environmental Management - Integrating environmental Aspects into pro-duct design and development. (2001).

[9] Yarwood, J. \& Eagan, P. (1998). Design for Environment: A Competitive Edge for the Future. MN Office of Environmental Assistance.

[10] Wimmer, W., Pamminger, R., Stachura, M. \& Grab, R. (2005). Ecodesign in the electronics industry - achieving legal compliance with the EU-directives and environmentally improving products by using the new EEE-PILOT. Fourth International Symposium on Environmentally Conscious Design and Inverse Manufacturing Eco Design, 671-677. https://doi.org/10.1109/ECODIM.2005.1619321

[11] Lindahl, M. (2006). Engineering designers' experience of design for environment methods and tools - requirement definitions from an interview study. Journal of Cleaner Production, 14, 487-496. https://doi.org/10.1016/j.jclepro.2005.02.003

[12] Tingström, J. \& Karlsson, R. (2006). The relationship between environmental analyses and the dialogue process in product development. Journal of Cleaner Production, 14(15-16), 1409-1419. https://doi.org/10.1016/j.jclepro.2005.11.012

[13] Spicer, A. \& Wang, M. H. (1997). Environmental design industrial template (EDIT): a software tool for analysis of product retirement. Journal of Cleaner Production, 5(3), 193-198. https://doi.org/10.1016/S0959-6526(97)00029-2

[14] Finnveden, G. \& Moberg, A. (2005). Environmental systems analysis tools - an overview. // Journal of Cleaner Production, 13, 1165-1173. https://doi.org/10.1016/j.jclepro.2004.06.004

[15] Rydberg, T. (1995). Cleaner products in the Nordic countries based on the life cycle assessment approach: the Swedish product ecology project and the Nordic project for sustainable product development. Journal of Cleaner Production, 3(1-2), 101-105. https://doi.org/10.1016/0959-6526(95)00063-K

[16] Luttropp, C. \& Lagerstedt, J. (2006). EcoDesign and the ten golden rules: generic advice for merging environmental aspects into product development. Journal of Cleaner Production, 14, 1396-1408. https://doi.org/10.1016/j.jclepro.2005.11.022

[17] Van Der Zwan, F. \& Bhamra, T. (2003). Alternative function fulfilment: incorporating environmental considerations into increased design space. Journal of Cleaner Production, 11(8), 897-903. https://doi.org/10.1016/S0959-6526(02)00161-0

[18] Van Hemel, C. (2002). Barriers and stimuli for ecodesign in SMEs. Journal of Cleaner Production, 10(5), 439-453. https://doi.org/10.1016/S0959-6526(02)00013-6

[19] Grajewski, D., Diakun, J., Wichniarek, R., Dostatni, E., Buń, P., Górski, F. \& Karwasz, A. (2015). Improving the Skills and Knowledge of Future Designers in the Field of Ecodesign Using Virtual Reality Technologies. Procedia Computer Science, 75, 348-358. https://doi.org/10.1016/j.procs.2015.12.257

[20] Anišić, Z., Ivica, V., Suzić, N., Sremčev, N. \& Orčik, A. (2013). Improving product design with IPS-DFX methodology incorporated in PLM software. Tehnički vjesnik, 20(1), 183-193.

[21] AutoDesk Sustainable Materials Assistant www.labs.autodesk.com/technologies/sustainable_materials assistant. (2010). 
[22] Information materials on SolidWorks Sustainability, Dassault Systemes. (2013).

[23] Novak, M. (2012). Computer aided decision support in product design engineering. Tehnički vjesnik, 19(4), 743-752.

[24] Dostatni, E., Diakun, J., Grajewski, D., Wichniarek, R. \& Karwasz, A. (2015). Multi-agent System to Support Decision-Making Process in Ecodesign. $10^{\text {th }}$ International Conference on Soft Computing Models in Industrial and Environmental Applications, 368, 463-474. https://doi.org/10.1007/978-3-319-19719-7_40

[25] Dostatni, E., Karwasz, A. \& Diakun, J. (2013). Method for estimating recycling costs of household appliances at product design stage. Innovation in management and production engineering, 298-306.

[26] Dostatni, E., Diakun, J., Karwasz, A., Grajewski, D. \& Wichniarek, R. (2014). Ecodesign of products in CAD $3 D$ environment with the use of agent technology. Publishing House of the Poznań University of Technology, Poznań.

[27] Wooldridge, M. (2002). An Introduction to multiagent system. John Wiley \& Sons.

[28] Zawadzki, P., Kowalski, M., Wichniarek, R. \& Kliński, G. (2014). Automatyzacja procesu projektowania rur giętych w oparciu o parametryczny system CAD. Mechanik, 2.

[29] Zawadzki, P. (2013). Automatic design of variant products with application of knowledge-based techniques. Inżynieria Maszyn, 18, 30-39.

[30] Górski, F., Hamrol, A., Kowalski, M., Paszkiewicz, R. \& Zawadzki, P. (2011). An automatic system for 3D models and technology process design. Transactions of Famena, 32(2), 69-78.

\section{Contact information:}

\section{Radosław WICHNIAREK, Ph.D.}

Chair of Management and Production Engineering

Poznan University of Technology

Piotrowo 3, 60-965 Poznań, Poland

E-mail: radoslaw.wichniarek@put.poznan.pl

\section{Damian GRAJEWSKI, M.Sc. Eng.}

Chair of Management and Production Engineering

Poznan University of Technology

Piotrowo 3, 60-965 Poznań, Poland

E-mail: damian.grajewski@put.poznan.pl

\section{Jacek DIAKUN, Ph.D.}

Chair of Management and Production Engineering

Poznan University of Technology

Piotrowo 3, 60-965 Poznań, Poland

E-mail: jacek.diakun@put.poznan.pl

\section{Ewa DOSTATNI, Ph.D.}

Chair of Management and Production Engineering

Poznan University of Technology

Piotrowo 3, 60-965 Poznań, Poland

E-mail: ewa.dostatni@put.poznan.pl

\section{Anna KARWASZ, Ph.D.}

Chair of Management and Production Engineering

Poznan University of Technology

Piotrowo 3, 60-965 Poznań, Poland

E-mail: anna.karwasz@put.poznan.pl 